\title{
Características e habilidades no ambiente digital: a cultura participativa sob os aportes de Jenkins e Murray
}

CHARACTERISTICS AND SKILLS IN THE DIGITAL ENVIRONMENT: THE CONTRIBUTIONS OF Jenkins AND MurRay tO participatory CULTURE

L Alan César Belo Angeluci

Doutor em Ciências com ênfase em Sistemas Eletrônicos pela Escola Politécnica da Universidade de São Paulo - EPUSP, com bolsa Doutorado Sanduíche na University of Brighton, Inglaterra. Pós-doutorado no Department of Radio-Television-Film, University of Texas at Austin (EUA). Mestre em Televisão Digital pela Universidade Estadual Paulista Júlio de Mesquita Filho - UNESP. Bacharel em Comunicação Social - Habilitação em Jornalismo pela mesma Instituição. Pesquisador do Centro Interdisciplinar em Tecnologias Interativas da USP (CITI-USP) e da Escola do Futuro (EF-USP). Professor na Escola de Comunicação da USCS. aangeluci@usp.br

Recebido em 23 de janeiro de 2014. Aprovado em 8 de setembro de 2014

\section{Resumo}

Neste artigo, busca-se discutir a cultura contemporânea a partir dos aportes conceituais explorados por Murray (2003) e Jenkins (2006), fundamentalmente no que tange ao digital como locus de uma cultura pautada pela participação coletiva dos indivíduos. Partindo da perspectiva da convergência das mídias e das literacias digitais, essa discussão centra-se nas transformações das práticas comunicativas dentro dos sistemas de mídias, em que determinadas características e habilidades são condições sine qua non para a participação efetiva na cultura digital. No que tange às características, discute-se principalmente o digital como procedimental, participativo, espacial e enciclopédico. Em relação às habilidades, é dada ênfase às de experimentação, flexibilidade, simulação, apropriação, multitarefa, cognição distribuída, inteligência coletiva, julgamento e navegação transmídia.

Palavras-chave: cultura participativa; características e habilidades; ambiente digital. 


\section{Abstract}

In this paper, the contemporary culture is discussed from the conceptual approach of Murray (2003) and Jenkins (2006), fundamentally regarding the digital as the locus of a culture based on the collective participation of individuals. From the media convergence and digital literacies perspective, the center of this discussion is on the transformation of communication practices within the media systems, in which some characteristics and abilities are mandatory conditions for an effective participation in digital culture. In relation to the characteristics, the discussion is mainly about the digital as procedural, participatory, spatial and encyclopedic. In terms of abilities, the emphasis is on the play, performance, simulation, appropriation, multitasking, distributed cognition, collective intelligence, judgment, transmedia navigation, network and negotiation.

Keywords: participatory culture; characteristics and abilities; digital environment.

\section{Introdução}

A compreensão do cenário cultural contemporâneo passa, ao menos em parte, pelo esforço de mapeamento de uma complexa relação que tem se estabelecido entre os indivíduos e os conteúdos digitais nos últimos anos, sobretudo a partir das mudanças socioeconômicas aventadas pela disseminação das redes de Internet no mundo. Mais recentemente, o terreno convergente das novas mídias alavancado pela era da Internet das Coisas (IoT) tem trazido novos desafios, já que os usuários são expostos, de maneira cada vez mais intensa, a várias experiências inovadoras em seus cotidianos, sejam elas através de novos dispositivos, novas plataformas ou novas aplicações.

A literatura busca situar essa cultura do digital por meio de diversas abordagens. Alguns autores (Lemos, 2002; SANTAella, 2003; Primo, 2007) se reportam à cibercultura e aos modelos cognitivos que se ressignificam nesse ambiente, dando destaque ao aspecto de coletivo participativo que pauta as práticas comunicativas. Neste artigo, busca-se localizar esta cultura participativa dentro da perspectiva da convergência das mídias e das literacias digitais, suscitando sua discussão com foco nas características do digital descritas por Murray (2003): o procedimental, o participativo, o espacial e o enciclopédico. Ademais, a visão de Jenkins (2006) sobre as habilidades necessárias neste ambiente é explorada, buscando nas transformações das mídias contemporâneas traços que revelem processos de experimentação, flexibilidade, simulação, apropriação, multitarefa, cognição distribuída, inteligência coletiva, julgamento e navegação transmídia.

Espera-se que a presente discussão contribua para melhor moldurar os futuros desafios e oportunidades em que plataformas de mídia e indivíduos se plasmam em um processo perene de retroalimentação, aprendizado e construção de novas perspectivas e culturas. 


\section{A perspectiva das literacias digitais}

O campo do hibridismo contemporâneo parece se estabelecer como espaço importante de discussão sobre as habilidades e características dos indivíduos em localizar uma informação e transformá-la em conhecimento para benefício próprio. Ora, se as literacias da era do capitalismo industrial estavam relacionadas, sobretudo, às leituras de livros e jornais, no espaço híbrido contemporâneo ela se expressa a partir das novas mídias e dos novos dispositivos de comunicação móvel e das redes, mudando, então, o foco da literacia de expressão individual para a do envolvimento coletivo.

Se partirmos de uma definição mais pragmática da literacia digital, podemos invocar a abordagem de Gilster (1997), que a definiu como uma extensão lógica do conceito original de literacia, da mesma forma sendo o hipertexto uma extensão da experiência tradicional de leitura. No entanto, o cenário contemporâneo exige um olhar mais caleidoscópico sob os eventos relacionados às habilidades dos indivíduos em acessar uma informação e transformá-la em conhecimento.

Tal qual destacam Passarelli \& Angeluci (2013), as literacias emergentes propiciadas a partir do ambiente $w e b$ levam a processos de produção e recepção coletivos em direção a um conhecimento em rede. As características e habilidades relacionadas ao mundo digital se estabelecem então a partir da interação e da comunicação dos indivíduos com as TVs interativas, games, smartphones, apps e tantas outras mídias tangíveis e intangíveis. Finalmente, ainda se faz válida sua definição mais expandida e pluralística que considera as várias práticas de literacia embarcadas em diferentes processos culturais, circunstâncias pessoais e estruturas coletivas (UNCTAD, 2004).

\section{Novas práticas comunicativas, novas mídias convergentes}

Se na contemporaneidade emergem literacias potencializadas pela prática colaborativa e em rede, estas práticas se tornam significativamente evidentes no âmbito da interação e comunicação. Manovich (2005) destaca a função das novas mídias nesse ambiente, catalizadoras da (re)construção de relações entre o indivíduo, suas práticas culturais e o computador. Aliás, este último exerce uma função de destaque, já que é a síntese do paradigma tecnológico atual. É a partir dele que novas formas de expressão do indivíduo e do coletivo passaram a ser factíveis, já que o conceito de conteúdo expandiu-se nas formas de bits e de dados digitais, mutáveis, reproduzíveis, rearranjáveis, remixáveis, em síntese, líquidos (BAUMAN, 2001).

$\mathrm{O}$ contexto das novas mídias também traz à tona a discussão das plataformas interoperáveis e convergentes. A transformação pela qual os sistemas de mídia tem 
experienciado passa não somente pela ótica da plena superação dos antigos modelos comunicacionais (funcionalista-pragmático, crítico-radical, entre outros), mas, também, pelas novas possibilidades técnicas que permitem o uso convergente de plataformas e trocas síncronas e/ou assíncronas de conteúdos, individuais e/ou em grupo.

Observa-se, portanto, a possibilidade da interatividade e do compartilhamento, em diversos níveis, entre indivíduos e máquinas. O fenômeno da segunda tela, por exemplo, pode ser um bom exemplo de como a atenção do indivíduo é competida por diversas telas (games, TV interativa, smartphones), gerando distintos usos, apropriações e comportamentos por parte dos usuários (ANGELUCI, 2013).

\section{As características do digital na concepção de Janet Murray}

Vemos, então, que as literacias digitais encontram terreno fértil no campo das novas mídias, já que coloca o indivíduo em interação contígua com o computador. Este aparato tecnológico acaba por atuar como facilitador de práticas comunicacionais mais efetivas e criativas. Murray (2003) também aborda o digital com perspectiva similar a de Manovich (2005), quando trata o aspecto da convergência como resultado de um avanço computacional exponencial:

O computador ligado em rede atua como um telefone, ao oferecer comunicação pessoa-a-pessoa em tempo real; como uma televisão, ao transmitir filmes; um auditório, ao reunir grupos para palestras e discussões; uma biblioteca, ao oferecer grande número de textos de referência; um museu, em sua ordenada apresentação de informações visuais; como um quadro de avisos, um aparelho de rádio, um tabuleiro de jogos e, até mesmo, como um manuscrito, ao reinventar os rolos de textos dos pergaminhos (MurRAY, 2003, p. 41).

No entanto, poderia ser um equívoco dizer que o lugar do digital na cultura contemporânea se encerra em si mesmo. O ambiente digital vai além da mera existência do conteúdo em dados de bits, reproduzíveis e flexíveis, e introduz na cultura participativa experiências inovadoras no campo do interativo e do imersivo - também identificados por autores como Lévy (2005). Produtos mercadológicos que exploram a realidade virtual e aumentada, o 3D, o intercâmbio e o compartilhamento de conteúdos via banda larga ou bluetooth são evidências dessas duas grandes bases da cultura participativa e que buscam explorar o sentido de agência ${ }^{1}$ nos indivíduos. Segundo Murray (2003), o ambiente

1 Segundo Murray (2003), agência trata-se da "capacidade gratificante de realizar ações significativas e ver os resultados de nossas decisões e escolhas".

\footnotetext{
$54 \frac{\text { Comunicação \& Inovação, PPGCOM/USCS }}{\text { v. 15, n. } 29 \text { (51-60) jul-dez } 2014}$
} 
digital, portanto, se expressa a partir de quatro principais características: o procedimental, o participativo, o espacial e o enciclopédico.

\section{a) Procedimental}

Vistos simplistamente como máquinas, os computadores parecem se resumir a um aparato capaz de realizar ações pré-ordenadas, disparando um conjunto de regras e métodos racionais que garantem seu devido funcionamento diante de uma demanda programada. Sua natureza procedural, de execução de cálculos precisos e rápidos, encontra na interação com o homem a reatividade, já que, para além da transmissão de informações estáticas, ele é capaz de assimilar comportamentos complexos e aleatórios, reagindo e respondendo às ações de interação com o usuário. Murray (2003) afirma que essa característica dos computadores os tornam cativantes, já que mimetizam a interlocução que ocorre entre os indivíduos no mundo real - até com um grau maior de acurácia, já que são dotadas de mecanismos de engenho maquinário.

Recentemente, o filme Ela (Her, Spike Jonze, 2013) explora este potencial procedimental das novas mídias a partir de uma perspectiva surreal da sociedade contemporânea sócio-técnica. Seguindo uma perspectiva similar de Admirável Mundo Novo de Aldous Huxley, publicado em 1932, o filme de Spike Jonze, por sua vez, centra-se nos conflitos de uma sociedade submetida às práticas programadas e de uma inteligência artificial de sistemas operacionais, que passam a interagir com os indivíduos em níveis cada vez mais profundos (Figura 1). A eficiência e o caráter procedimental da máquina extrapolam as fronteiras do participativo e da interação, o que suscita a discussão sobre um futuro mensurado por configurações de relacionamento homem-máquina um tanto quanto polêmicas.

\section{b) Participativo}

O exemplo de Ela nos leva a um segundo aspecto do ambiente digital, que é a capacidade de reação aos dados que nele inserimos. O digital, portanto, reconstitui codificadamente respostas dos comportamentos humanos. Neste ponto, destacamos a ideia de Lévy (p. 79, 1999) que enfatiza a "participação ativa do beneficiário de uma transação de informações". O potencial participativo permite, por exemplo, a exploração do sentido de agência no indivíduo, uma vez que suas ações trazem respostas às demandas do mesmo.

O uso do filtro no aplicativo Instagram, por exemplo, ilustra a participação ativa do indivíduo na construção de uma realidade a partir do potencial participativo do ambiente digital: a coloração do céu (Figura 2) adquire sentidos diferentes de acordo com as reações do indivíduo ao sistema. 


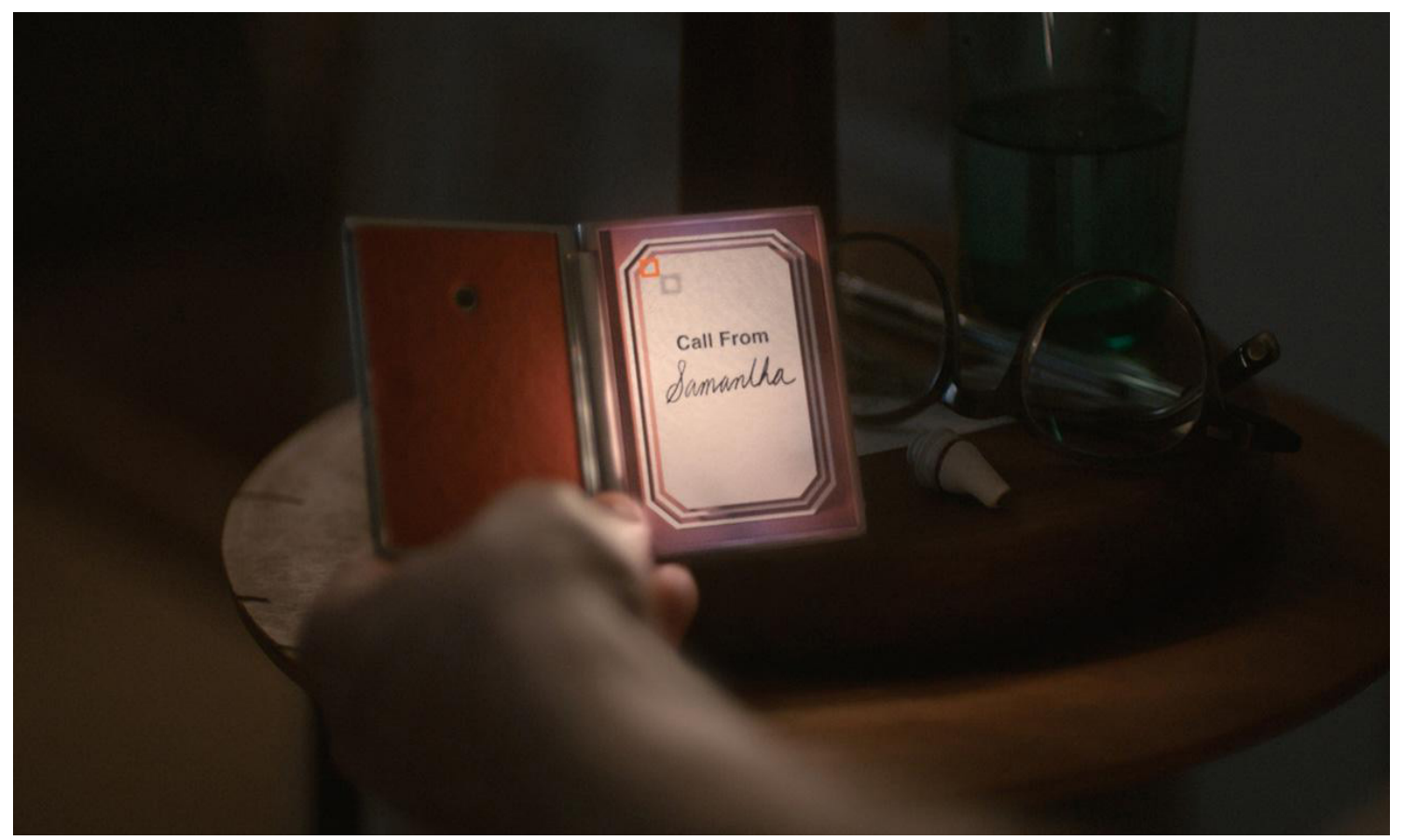

Figura 1: Still de cena do filme Her em que o SO Samantha busca diálogo com seu "dono".

Fonte: Trailer disponível em <https://www.youtube.com/watch?v=WzV6mXIOV14>. Acesso em: 11 Fev 2014.

\section{c) Espacial}

O caráter espacial talvez se revele como o mais evidente do ambiente digital, visto que toca no âmbito da navegabilidade dos sistemas digitais e se configuram como um dos aspectos distintivos do virtual. Para Murray (2003), o fluxo não linear, com diferentes pontos de partidas e chegadas, cria uma experiência de navegação diferente da dos livros e filmes, que também tem a possibilidade de criar estes espaços através do verbal e do imagético. O digital, no entanto, coloca o indivíduo na centralidade das ações e, como ocorre com o uso da web através dos browsers dos computadores desktops ou dispositivos móveis, permite que o indivíduo construa seu próprio sentido e narrativa, amparado em seu repertório.

\section{d) Enciclopédico}

O caráter enciclopédico identificado por Murray (2003) situa-se no campo do acesso aos conteúdos, já que as representações do mundo têm migrado para o formato eletrônico e uma gama de dados passam a se tornar disponíveis na nuvem e consultáveis de qualquer parte do globo terrestre.

Bancos de dados, bibliotecas de conteúdos, ferramentas de gestão e interação e tantos outros conteúdos se expandem em termos de acesso e quantidade, já que, da mesma forma, computadores e redes se disseminam e se multiplicam em quantidade e variedade, 


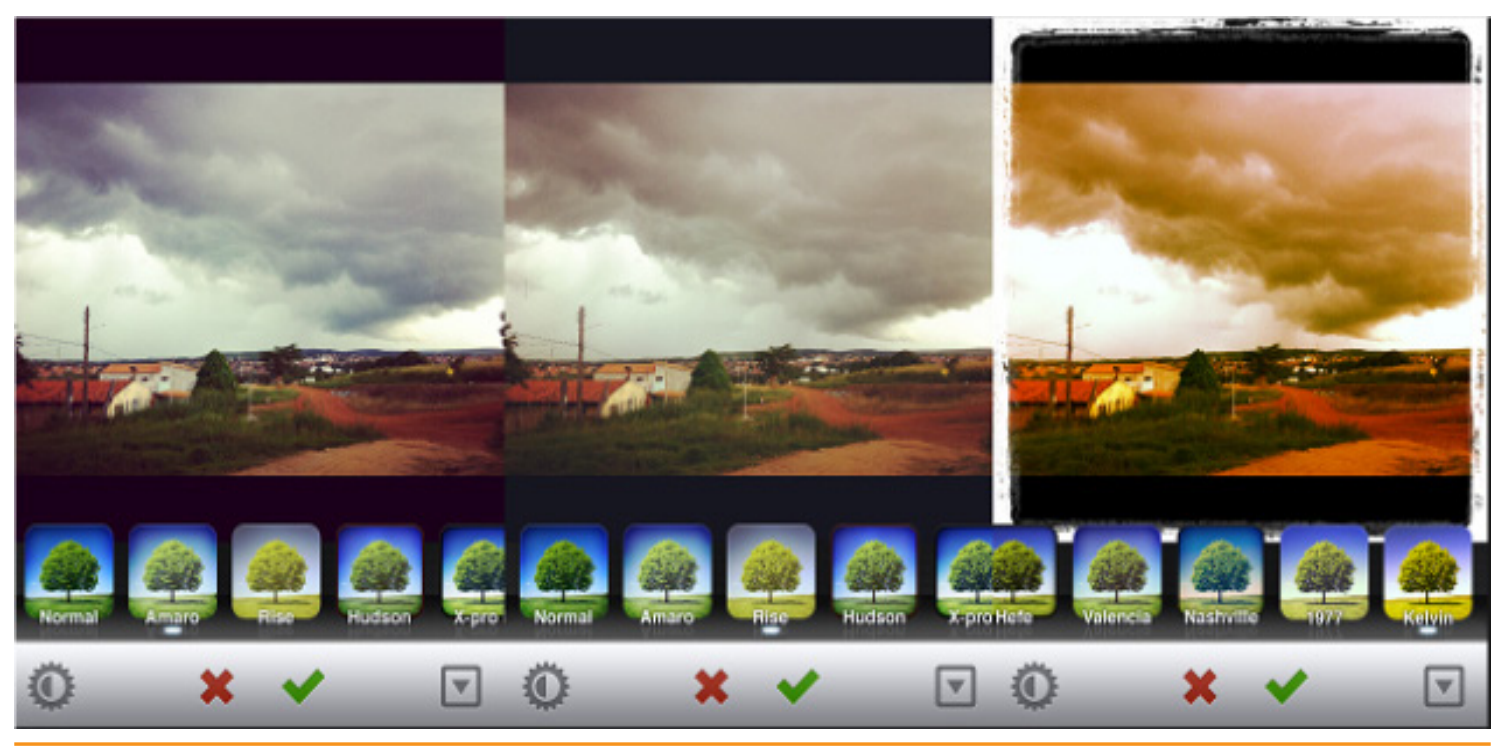

Figura 2: Exemplo das possibilidades de filtros no Instagram Fonte: www.techtudo.com.br

em uma perspectiva exponencial rizomática e não linear de expansão potencializadas pela conectividade.

\section{As habilidades do digital na concepção de Henry Jenkins}

Na cultura participativa enunciada por Jenkins (2006) há uma clara preocupação em se discutir o digital superando questões meramente tecnológicas de acesso em direção às oportunidades de participar do desenvolvimento cultural de competências e habilidades sociais necessárias para seu pleno envolvimento. Recuperando, portanto, o conceito de literacias, Jenkins (2006) propõe o que se define como New Media Literacies (NML), evidenciando competências concernentes às novas mídias imersas no ambiente digital.

\section{a) Experimentação}

A habilidade de experimentação resume-se à capacidade de um indivíduo de explorar um ambiente a fim de resolver problemas. Navegar na web pura e simplesmente, por exemplo, não colabora para a compreensão do conceito, já que o "experimentar" pressupõe uma atitude pró-ativa do indivíduo em localizar a fonte adequada para cada objeto de busca, bem como o uso do dispositivo adequado para determinadas situações.

Como exemplo, um indivíduo poderá ter mais sucesso na busca de cheats e codes para um game dentro de fóruns especializados do que em bases de artigos científicos. No entanto, sua capacidade de exploração de novos ambientes pode ajudá-lo a garimpar 
e identificar informações em áreas que, a princípio, pareciam em nada colaborar em sua busca.

\section{b) Flexibilidade}

A habilidade de flexibilidade se revela quando são adotadas identidades alternativas com foco na improvisação e nas descobertas. Partindo do mesmo exemplo do game, desta vez usando o Second Life como base, o jogador passa a assumir características de um personagem fictício e o assume como si mesmo durante o desenrolar da narrativa. Toda a complexidade de construção e elaboração dessa identidade deve ser considerada, visto que quanto maior o detalhamento, melhor o nível de criação e, portanto, de imersão na realidade virtual.

\section{c) Simulação}

Dentro da mesma lógica, a habilidade de observar, inserir-se, decodificar e remixar modelos dinâmicos de processos do mundo real evidenciam a capacidade do indivíduo que interage bem com sistemas de simulação de realidade. Sistemas de simulação são, por vezes, capazes de expandir competências cognitivas.

\section{d) Apropriação}

Apropriar-se de um conteúdo de mídia com vistas a sua experimentação e reorganização dentro do ambiente digital parece ser uma habilidade bastante recorrente no ambiente digital. A cultura do mash up exponenciada pelo potencial de disseminação das mídias sociais de vídeo - o Youtube, por exemplo - traz à tona a figura do prosumer preconizada por Toffler (2007).

\section{e) Multitarefa}

O jovem contemporâneo carrega em seu repertório a habilidade de escanear o ambiente e mudar o foco, conforme a necessidade, para detalhes de seu interesse. Desta forma, o uso de múltiplas telas de interação coloca a habilidade de multitarefa em destaque, já que, capaz de migrar rapidamente de uma tela a outra, o jovem tende a construir uma realidade baseada na aquisição de informações por variadas e alternadas fontes.

\section{f) Cognição distribuída}

$\mathrm{O}$ uso de ferramentas de $\mathrm{EaD}$, moodle, fóruns de discussão e aplicativos interativos colaborativos evidenciam a habilidade de interagir significativamente com ferramentas que ampliam capacidades mentais. A percepção de cognição distribuída, inclusive, 
contaminou instituições tradicionais de ensino, que têm investido em ferramentas de educação on-line diante da configuração desta paisagem digital.

\section{g) Inteligência coletiva}

A habilidade da inteligência coletiva associa-se a outras já previamente listadas, visto que toca na capacidade de coletar e reunir conhecimentos, comparar dados com coletivos e direcionar-se a objetivos comuns.

\section{h) Julgamento}

Discernir e avaliar a confiabilidade e credibilidades de diferentes fontes de acesso à informação torna-se uma relevante habilidade no ambiente digital, visto que o crescimento exponencial da web e dos servidores coloca à disposição do indivíduo uma gama imensa de informações que demandam filtros e seleções criteriosas.

\section{i) Navegação transmídia}

Conteúdos transmídias são a expressão das mais evidentes do ambiente digital. A capacidade convergente das plataformas, ubiquidade e pervasão de suas mídias geram possibilidades de interação e compartilhamento de conteúdos em diferentes níveis e esferas. Demanda, desta forma, a habilidade de seguir o fluxo de histórias e informações por meio de múltiplas modalidades. A estratégia transmídia tem se revelado como o grande "coringa" da contemporaneidade no campo das novas mídias.

\section{Considerações Finais}

O locus do digital na cultura participativa revela-se quando sua efetiva prática evidencia suas características e as habilidades necessárias para se atuar neste ambiente. Murray (2003) e Jenkins (2006) contribuem com essa reflexão ao descrever a experiência do digital tomando como um ponto de partida comum a ideia do interativo e do imersivo como inescapáveis práticas contemporâneas. Terreno em que o indivíduo encontra-se também no coletivo e vice-versa, em que as figuras do produtor e receptor se plasmam e se apoiam no processo de criação e compartilhamento; terreno em que barreiras à expressão artística e ao engajamento se tornam mais facilmente transponíveis.

O digital, dessa forma, parece encontrar-se na expressão de um cenário cultural contemporâneo em que produção, distribuição e recepção de conteúdos estão submetidas a uma lógica participativa. Uma lógica, por um lado, meramente modular, automática, 
representável numericamente, variável e transcodificável; mas de outro, espaço de representação de um coletivo humano, repleto de sentidos, emoções, sentimentos e vida.

\section{Referências}

Angeluci, A. C. B. "From Gads to Apps: the key challenges of post-web internet era". Revista GEMInIS, v. 1, p. $75-88,2013$.

Bauman, Z. Modernidade liquida. Rio de Janeiro, Brazil: Editora Zahar. 2001.

Gilster, P. Digital literacy. San Francisco, CA: John Willey \& Sons. 1997.

Jenkins, H. Confronting the challenges of participatory culture: media education for the $21^{\text {st }}$ Century. MacArthur Foundation, 2006. Disponível em: http://www.newmedialiteracies.org/wp-content/ uploads/pdfs/NMLWhitePaper.pdf. Acesso em 12 fev. 2014.

Cultura da Convergência. São Paulo: Aleph, 2008.

MANOVICH, L. "Novas mídias como tecnologia e ideia: dez definições”. In: LEÃO, Lúcia (org.). O chip e o caleidoscópio: reflexões sobre as novas mídias. São Paulo: Editora Senac, 2005.

Murray, J. Hamlet no Holodeck: o futuro da narrativa no ciberespaço. Tradução de Elissa Khoru Daher, Marcelo Fernandez Cuzziol - São Paulo: Itaú Cultural: Unesp, 2003.

Lemos, A. Cibercultura. Porto Alegre: Sulina, 2002.

LÉvy, P. Cibercultura. $1^{\text {a }}$ ed. São Paulo: Editora 34, 1999.

Passarelli, B.; Angeluci, A. C. B. "Interactive Generation Brazil research: children and teenagers using computers, TV, games and mobile phones". In: Jamil, G. L.; Malheiro, A.; Ribeiro, F. Rethinking the Conceptual Base for New Practical Applications in Information Value and Quality. IGI Global, New York, EUA, 2013.

Primo, A. Interação mediada por computador: comunicação, cibercultura, cognição. Porto Alegre: Sulina, 2007.

Santaella, L. Cultura e artes do pós-humano. São Paulo: Editora Paulus, 2003.

Toffler, A. A terceira onda. 29a ed., Rio de Janeiro: Record, 2007.

REGIS, F.; Timponi, R.; MAIA, A. “Cognição integrada, encadeada e distribuída: breve discussão dos modelos cognitivos na cibercultura". Revista Comunicação, Mídia e Consumo. São Paulo, ano 9, v. 9, n. 26, p.115-134, nov. 2012.

UNCTAD. Measuring the impacts of information and communication technology for development. New York: United Nations. 2011.

$60 \frac{\text { Comunicação \& Inovação, PPGCOM/USCS }}{\text { v. 15, n. } 29 \text { (51-60) jul-dez } 2014}$ 